\title{
Associations between neighborhood violence during pregnancy and birth outcomes: evidence from São Paulo's Western Region Birth Cohort
}

\author{
Angélica Carreira dos Santos ${ }^{1 *}$ (D), Alexandra Brentani ${ }^{1}$ and Günther Fink ${ }^{2}$
}

\begin{abstract}
Background: Low birth weight and prematurity remain leading causes of infant mortality and morbidity globally. Although extensive literature has highlighted the importance of socioenvironmental characteristics for birth outcomes, the role of indirect violence on health remains fairly understudied.

Methods: Using geocoded birth records from the ongoing Western Region Birth Cohort (Região Oeste Coorte ROC-Cohort) of infants born between 2012 and 2014 and geocoded crime reports, we assessed the associations between exposure to violent crimes during pregnancy within a 1-km radius of the mother's residence and low birth weight, preterm delivery, and being born small-for-gestational-age. Violent crime exposure was categorized into quintiles. Multivariate logistic regressions were used to examine the associations between violence exposure and birth outcomes. Models were adjusted for sex, maternal age and education, socioeconomic status, and risk factors such as hypertension, diabetes, smoking, and drinking during pregnancy.

Results: Among the 5268 children included, the average crime exposure during the first two trimesters of pregnancy ranged from 0.44 violent crimes in the least exposed quintile to 12.74 crimes in the most exposed. Compared to children with the lowest violence exposure, children in the highest exposure quintile had higher odds of being born small-for-gestational-age (1.41[1.06-1.89]), preterm (1.35[1.01-1.80]), and low birth weight (1.42[1.031.98]). While socioeconomic status and maternal education were positively associated with lower violence exposure, no associations were found between these characteristics and birth outcomes.

Conclusions: Higher exposure to violent crimes in the close vicinity of pregnant women's residence is associated with substantial increases in the odds of adverse birth outcomes. Policies to improve neighborhood safety can potentially contribute not only to the short-term wellbeing of populations but may also have large social, economic, and health benefits in the long term.
\end{abstract}

Keywords: Violence, Pregnancy, Child health, Birth weight, Social determinants of health

* Correspondence: angelica.carreira@gmail.com

1 Department of Pediatrics, University of São Paulo Medical School, Av. Dr.

Enéas Carvalho de Aguiar, 647, São Paulo CEP-01246-904, Brazil

Full list of author information is available at the end of the article

C C The Author(s). 2021 Open Access This article is licensed under a Creative Commons Attribution 4.0 International License, which permits use, sharing, adaptation, distribution and reproduction in any medium or format, as long as you give appropriate credit to the original author(s) and the source, provide a link to the Creative Commons licence, and indicate if changes were made. The images or other third party material in this article are included in the article's Creative Commons licence, unless indicated otherwise in a credit line to the material. If material is not included in the article's Creative Commons licence and your intended use is not permitted by statutory regulation or exceeds the permitted use, you will need to obtain permission directly from the copyright holder. To view a copy of this licence, visit http://creativecommons.org/licenses/by/4.0/. The Creative Commons Public Domain Dedication waiver (http://creativecommons.org/publicdomain/zero/1.0/) applies to the data made available in this article, unless otherwise stated in a credit line to the data. 


\section{Background}

Low birth weight accounts for more than $80 \%$ of all neonatal mortality globally [1]. In 2015, more than 1 million children under 5 died because of preterm birth complications globally [2]. Neonates born with low birth weight - about two-thirds of which are preterm [1] - face higher morbidity risks, increased risk of stunting, increased risk of long-term development impairment, as well as increased vulnerability to chronic disease [1-7].

Violence is a growing public health concern with immediate and long-term influences on population health [8-10]. Contrary to some positive trends observed in high-income countries (HIC) in recent years [10], homicide rates have been increasing in Latin America over the past years [11]. An estimated homicide rate of 28.5 implies that Latin America's crime rates are approximately 8 times higher than those seen in HICs on average and 14 times those seen in low-middle-income countries (LMICs) in the Western Pacific Region [11].

Exposure to violence has been consistently associated with mental health problems and high-risk behaviors such as alcohol, smoking, and drug abuse, which threaten the wellbeing of both adult and child populations $[9,12]$, and which are also well-known risk factors for low birth weight, small-for-gestational-age, and preterm birth. Fear of crime can trigger anxiety and feelings of isolation, victimization, powerlessness, and normlessness [13], particularly among women [14]. Moreover, stress may indirectly increase the risk of adverse birth outcomes through the development of depressive symptoms and low commitment to prenatal care [15-18], and inadequate dietary intake [19].

Chronic exposure to such environmental stress can trigger neural or neuroendocrine responses, change the functioning of the hypothalamic-pituitary-adrenal (HPA) axis and lead to increased allostatic load [20]. Stress may also increase the placental secretion of corticotrophinreleasing hormones, which increase prostanoids and stimulate uterine contractions and can induce preterm delivery [17, 20-23]. Studies have also shown that increased activation of the maternal HPA axis and sympathetic nervous systems can induce restrictions in uterine vasculature, resulting in intrauterine growth restriction or preterm birth [7].

A growing body of literature has tried to link external violence's to adverse birth outcomes at the area level [24-33]. The large majority of studies are based on neighborhood comparisons in the United States and likely allow only limited insight into the impact of violence in low-income settings due to the large structural differences in neighborhoods and public support systems. The few studies that have been conducted in lowincome and high crime exposure areas have mostly focused on sociopolitical violence and generally found sizeable increases in adverse birth outcomes in response to major violence outbreaks $[24,34,35]$. This is consistent with other studies focusing on more extreme forms of violence, such as terrorist attacks and civil/war conflicts, generally finding large increases in the risk of pregnancy complications outcomes after such major events [24, 36, 37]. Moreover, the effects of violence on adverse birth outcomes might differ from areas where violence is rare and areas where violence is considered endemic, having each additional violent crime smaller adverse consequences on birth outcomes due to the process of adaptation [27].

In this paper, we aim to explore the relationship between exposure to violent crime in close vicinity and three of the most common adverse birth outcomes: preterm birth, small-for-gestational-age, and low birth weight in one of the largest metropolitan areas of the world [38]. Using a novel data set, we aim to improve the understanding of the health consequences of violent crimes on pregnant women and their offspring in a lowincome population. Our initial hypothesis is that the occurrence of violent crime close to home is associated with these adverse birth outcomes, independent of maternal and socioenvironmental characteristics.

\section{Methods \\ Study design}

This study was designed as a retrospective crosssectional study linking data collected as part of a prospective cohort study to geocoded administrative data on violent crime.

\section{Study setting}

This study was conducted in the municipality of São Paulo, Brazil. In São Paulo State, the proportion of preterm births increased from $7.7 \%$ in 2004 (7.7\%) to $12.4 \%$ in 2013 [39]. At the same time, preterm birth increased from $8.6 \%$ in 2004 to $11.6 \%$ in 2013 in the São Paulo municipality. In 2016, preterm rates were 10.9 and $10.7 \%$ in São Paulo State and São Paulo municipality, respectively [39]. Regarding low birth weight, both State and municipality had low variation across time, considering the available data, with the highest proportion observed in 2012, 9.5 and 9.7\%, respectively [40]. Data on children born small for gestational age is not publicly available for either area.

Like other LMICs, Brazil has experienced a rapid and mostly unmanaged urbanization process in the past decades, accompanied by large increases in social and economic inequality $[41,42]$. The rates of homicides in Brazil rose steadily over the past years, reaching a record level of 31.6 homicides per 100,000 inhabitants in 2017 [43]. With 10.3 homicides per 100,000 inhabitants, the São Paulo municipality had one of the lowest homicide 
rates in Brazil in 2017 overall, but still experienced very high crime rates in areas of low socioeconomic development [43]. In the Western Region of São Paulo, where this study was conducted, homicide rates ranged between 5 and 20 homicides per 100,000 inhabitants across neighborhoods [44].

\section{Study population}

The São Paulo Western Region Birth Cohort (Região Oeste Coorte - ROC-Cohort) enrolled locally resident babies born at the University Hospital of the School of Medicine of the University of São Paulo between April 1, 2012, and March 31, 2014. The study's main objective was to evaluate the impact of environmental and social determinants of health on child development. A total of 7066 births occurred in the period, and 6207 motherchild pairs who resided in the studied setting were enrolled in the cohort. Children were followed-up at 6 months, 12 months, and 36 months. The cohort is still active, and the 72 months (6 years) follow-up was paused due the ongoing COVID-19 pandemic. The follow-up rounds targeted all enrolled children who were alive at the time of the follow up. Assessments involved child development, mental health, health habits and status, parenting practices and general living conditions. A full description of the cohort can be found elsewhere [45].

\section{Data}

Hospital electronic birth records were available for all children in the cohort. The electronic medical registry includes birth characteristics such as type of delivery, gestational length, weight at birth, and others. During the postpartum hospital stay, all mothers were invited to complete a short-structured questionnaire administered by a trained interviewer to collect information on sociodemographic characteristics and health during pregnancy. The questionnaire was applied after maternal consent or a parent if the mother was too young to consent. The questionnaire can be found in Supplementary file 1 , and the rates of interview and process can be found in the cohort profile [45].

\section{Outcomes}

The analysis focused on three adverse birth outcomes: low birth weight (LBW), preterm delivery (PT), and small-for-gestational-age (SGA). Birth weight was measured by the Hospital's neonatology team immediately after birth using standard hospital equipment. Gestational length in weeks was estimated using the New Ballard Score [46]. LBW was defined as birth weight $<2500$ $\mathrm{g}$, and SGA was defined as weight-for-gestational age $<$ 10th percentile based on the Intergrowth-21st growth reference Tables [47].

\section{Exposure - violence in the neighborhood}

Data on violence is routinely collected and made publicly available by the Secretariat of Public Safety of the State of São Paulo and can be accessed on www.ssp.sp. gov.br. The system collects detailed information on all willful murders, femicides (gender-based murder), robberies followed by death, bodily injuries followed by death, deaths resulting from police intervention, suspicious deaths, fatal vehicle accidents, and cellphone and car theft occurring in São Paulo State. Data on other crimes such as intimate partner abuse (physical, emotional, financial), rape, and child sexual assault are not collected in this system.

Each reported incident record contains the date, time, and address of the crime. Following most of the external violence literature, we focused on violent crime in our analysis, which includes willful murder, robbery followed by death, bodily injury followed by death and death resulting from police intervention but excludes other crimes such as robberies without injuries. Feminicide was not included in the analysis because this data was only available after 2015 .

We extracted data on violent crimes between 2011 and 2014 to cover all ROC-Cohort children's pregnancy period. The address of each reported crime was geocoded with latitude and longitude coordinates using the ggmap package [48], and a point-layer for each time point (month-year) was generated using $\mathrm{R}$ map tools [49]. The maternal residential address was collected at birth and geocoded as an additional point-layer. Each residential address was treated as a centroid point. We then computed the number of crimes within a $1-\mathrm{km}$ spatial buffer by day, month, and year. Exposure to violence during pregnancy was estimated as the sum of violent crimes in the first two trimesters of pregnancy. Violence in the third trimester was not considered because total exposure to violence after week 24 of gestation directly depends on gestational length in weeks (the outcome variable). The sum of violent crimes within 1$\mathrm{km}$ of each mother's residence during the first two trimesters was categorized into five equally sized quintiles for analysis. This categorization was chosen to allow us to compare the $20 \%$ of births with the lowest external violence exposure to families in higher exposure quintiles. We provide a detailed discussion of the exposure differences between these quintiles below.

\section{Statistical analyses}

We first computed the average number of crimes for each of the exposure quintiles. Next, we tested crude associations of exposure to violence quintiles with each outcome (LBW, SGA, and PT birth). In the fully adjusted multivariable models, we included all covariates highlighted in the existent literature as risk factors for 
adverse birth outcomes, including maternal age $(<20$, $>=35$ ), educational level (incomplete primary, complete secondary and tertiary), alcohol consumption (yes/no), smoke (yes/no), diabetes (yes/no), hypertension (yes/no) and experience of physical violence (yes/no) during pregnancy - reported by the mother in the postpartum questionnaire, and socioeconomic (SES) index. The construction of a socioeconomic (SES) index was based on the approach proposed by Vyas and Kumaranayake [50], which relies on the use of principal component analysis (PCA) of the selected variables. The SES index was based on questions regarding asset holdings such as cars, family income, and household characteristics. The PCA's first principal component was then divided into five SES quintiles - low, medium-low, medium, medium-high, and high SES status. Maternal age was categorized into adolescence $(<20)$, core reproductive age $(22-34)$ and ages $>35$.

Given that the postpartum questionnaire was not available for the whole sample, we initially screened the dataset for missing data and patterns of nonresponsiveness in the postpartum questionnaire using $\mathrm{t}$ test and chi-square to test if the assumptions of missing at random (MAR) were met. The reasons for not completing the postpartum questionnaire vary from being too young to consent to being discharged before the interview could be completed. The details can be found elsewhere [45]. As the assumptions of MAR in our sample were met, we implemented the MICE to complete the missing data in the postpartum questionnaires to all cohort participants. We implemented multiple imputations by chained equations (MICE) with a fully conditional specification of prediction equations using variables that potentially predicted nonresponse or the outcome. The MICE method accounts for statistical uncertainty in the imputations and ensures more reliable inference in settings with missing data. All imputed models had a relative efficiency higher than $99 \%$.

We performed the MICE using Stata's mi package [51]. The variables used in the MICE models included exposures (e.g., violence during pregnancy), birth outcomes (PT, LBW and SGA), maternal characteristics (e.g., age, socioeconomic, education), pregnancy variables (e.g., diabetes, hypertension), and neonatal variables (e.g., birth weight, length, and sex). We generated 50 independent datasets $(M=50)$ and followed Rubin's rules to aggregate results across imputed datasets [52]. All analyses were performed using Stata version 14 [53]. Further details on these imputations are provided in Table S1 (Supplementary file 2).

\section{Results}

Among the 6207 children in the ROC-Cohort, 44 were stillbirths and excluded from the analysis. The likelihood of being stillborn was not associated with violence exposure during pregnancy in our sample $(0.99 ; 95 \% \mathrm{CI}$ : 0.92-1.06). Additionally, 895 mother-child dyads were excluded due to an address outside of the studied setting. Overall, 5268 children and their mothers met the inclusion criteria for this study.

Mothers who did not respond to the postpartum questionnaire $(n=2008)$ did not differ from those who completed $(n=3260)$ the survey with respect to the type of birth, gestational length category, birth weight and length, and child sex.

$398(7.8 \%)$ births were classified as SGA, $369(7.0 \%)$ as PT, and $355(6.7 \%)$ as LBW. Table 1 shows the frequency of each type of crime during pregnancy by exposure quintile. From 2011 to 2014, there were 8504 violent crimes in the São Paulo municipality - only 13 of these could not be geolocated (0.15\%). 339 (4\%) of all crimes in the municipality were located in the ButantaJaguaré area (where all children of the cohort reside). During the first two trimesters, the mean number of crimes occurring within a $1-\mathrm{km}$ radius from home was $4.2(\mathrm{SD} \pm 4.8)$. The large majority of violent crimes were murders; death resulting from police intervention was the second most common type of violent crime. Women with the lowest exposure quintile were on average exposed to 0.45 ( $\mathrm{SD} \pm 0.5$ ) violent crimes, while women in the fifth quintile were exposed on average to 12.7 (SD \pm 4.5 ) violent crimes. Only $19 \%$ of women were not exposed to any violent event in a $1 \mathrm{~km}$ radius during pregnancy; some women in the top exposure quintile experienced more than 30 violent crimes during the first two trimesters.

Figure 1 shows the geographic distribution of the outcomes and violent crimes in the studied area. Areas colored in red represent the highest crime exposure; blue areas are safest. Panel A of Figure one shows the overall spatial distribution of children in the study area. Panels $\mathrm{B}, \mathrm{C}$, and $\mathrm{D}$ illustrate the spatial distribution of the three adverse birth outcomes.

The prevalence of SGA, PT and LBW were 6.7, 7.9, and 9.5\% (SGA), 6.5, 6.4, and 6.3\% (PT), and 5.4, 7 and $7.5 \%$ (LBW) in the first, third, and fifth exposure quintiles, respectively. Table 2 shows the distribution of SGA, PT, and LBW birth outcomes and family characteristics by exposure quintile using the raw (non-imputed) data. The number of available data points for each variable as well as additional information on the MICE can be found in Supplementary file 2. Table 2 also shows the bivariate analysis between continuous violent crimes quintiles (range 1 to 5), and birth outcomes, and child and family characteristics. In bivariate analysis LBW was strongly associated with crime exposure (1.09; 95\%CI: 1.02-1.17, $p=0.014$ ), while PT and SGA displayed positive but not statistically significant 
Table 1 Mean number of violent crime type in pregnancy per exposure quintile.

\begin{tabular}{|c|c|c|c|c|c|}
\hline & 1st quintile & 2nd quintile & 3rd quintile & 4th quintile & 5th quintile \\
\hline & Mean \pm SD & Mean \pm SD & Mean \pm SD & Mean \pm SD & Mean \pm SD \\
\hline Murder & $0.39 \pm 0.49$ & $1.71 \pm 0.67$ & $2.64 \pm 0.71$ & $4.34 \pm 1.38$ & $9.08 \pm 2.85$ \\
\hline Assault followed by death & $0.26 \pm 0.65$ & $0.26 \pm 0.65$ & $0.29 \pm 0.65$ & $0.48 \pm 0.90$ & $0.65 \pm 1.50$ \\
\hline Bodily injury followed by death & $0.01 \pm 0.08$ & $0.02 \pm 0.12$ & $0.01 \pm 0.10$ & 0 & 0 \\
\hline Death resulting from police intervention & 0 & $0.01 \pm 0.16$ & $0.06 \pm 0.34$ & $0.22 \pm 0.64$ & $3.02 \pm 2.79$ \\
\hline
\end{tabular}

SD: standard deviation

associations with violent crimes. Upper middle (0.91; 95\%CI: $0.85-0.98, p=0.013)$ and high $(0.83 ; 95 \% \mathrm{CI}$ : $0.77-0.89, p<0.001)$ SES status was negatively associated with violent crimes. Physical violence during pregnancy reported in the postpartum questionnaire was also negatively associated with violent crimes (0.79; 95\%CI: 0.66-0.95, $\mathrm{p}=0.013$ ).

Figure 2 shows the bivariate relationship between exposure to violent crime and the proportion of infants born SGA (panel a), preterm (panel b) and LBW (panel c). Table 3 shows the unadjusted and adjusted associations between violent crime exposure during pregnancy and adverse birth outcomes. All models were adjusted using maternal age, child sex, education, and socioeconomic status. Relative to children from the lowest violence quintile, living in the highest violence quintile was associated with a $46 \%$ increase in SGA odds in the unadjusted model (1.46; 95\%CI: 1.10-1.93). After adjustment for covariates, risk factors, and SES status, the estimated odds ratio (OR) slightly decreased (1.41;

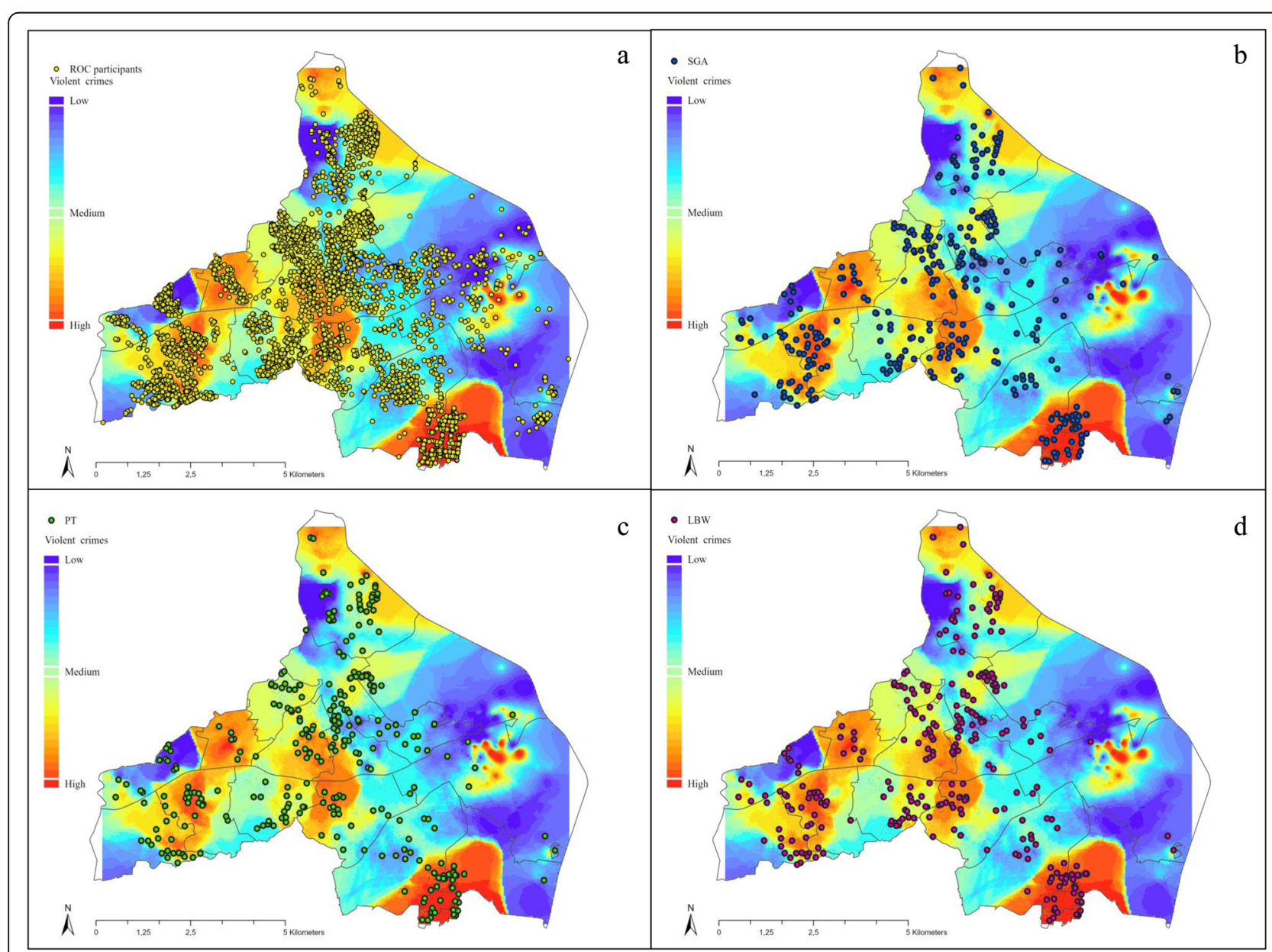

Fig. 1 Heatmap of the Butantã-Jaguaré Region of São Paulo showing the distribution of violent crimes during pregnancy. Blue indicates lower number of violent crimes incidents and red higher. The point layers show the geographic distribution of ROC residences (a), infants born small for gestational age (b), preterm births (c), and low birth weight (d) 
Table 2 Birth outcomes and child and family characteristics before multiple imputation by external violence exposure quintile, and the association between the pooled violent crimes quintiles and birth outcomes and child and family characteristics.

\begin{tabular}{|c|c|c|c|c|c|c|c|c|c|c|c|c|}
\hline \multirow{2}{*}{$\begin{array}{l}\text { Violent crimes quintile } \\
\text { Number of occurrences } \\
\text { Variables }\end{array}$} & \multicolumn{2}{|c|}{$\begin{array}{l}\text { 1st quintile } \\
\text { Low: } 0-1\end{array}$} & \multicolumn{2}{|c|}{$\begin{array}{l}\text { 2nd quintile } \\
\text { Lower-meddle: } 2\end{array}$} & \multicolumn{2}{|c|}{$\begin{array}{l}\text { 3rd quintile } \\
\text { Middle: } 3\end{array}$} & \multicolumn{2}{|c|}{$\begin{array}{l}\text { 4th quintile } \\
\text { Higher-middle: 4-7 }\end{array}$} & \multicolumn{2}{|c|}{$\begin{array}{l}\text { 5th quintile } \\
\text { High: } 8-37\end{array}$} & \multirow[t]{2}{*}{$\mathrm{OR}^{*}(95 \% \mathrm{Cl})$} & \multirow[t]{2}{*}{$\mathrm{p}$} \\
\hline & $\bar{n}$ & $\%$ & $\mathrm{n}$ & $\%$ & $\bar{n}$ & $\%$ & $\bar{n}$ & $\%$ & $\bar{n}$ & $\%$ & & \\
\hline \multicolumn{13}{|l|}{$\mathrm{SGA}(N=5080)$} \\
\hline Yes & 116 & 6.7 & 78 & 9 & 36 & 7.9 & 81 & 7.4 & 87 & 9.5 & $1.06(1.00-1.14)$ & 0.062 \\
\hline \multicolumn{13}{|l|}{ PT $(N=5268)$} \\
\hline Yes & 116 & 6.5 & 68 & 7.5 & 30 & 6.4 & 94 & 8.3 & 61 & 6.3 & $1.02(0.95-1.09)$ & 0.594 \\
\hline \multicolumn{13}{|l|}{ LBW $(N=5268)$} \\
\hline Yes & 96 & 5.4 & 66 & 7.3 & 33 & 7.0 & 88 & 7.7 & 72 & 7.5 & $1.09(1.02-1.17)$ & 0.014 \\
\hline \multicolumn{13}{|l|}{ Fetal sex $(N=5268)$} \\
\hline Female & 898 & 50.2 & 449 & 49.5 & 246 & 52.1 & 589 & 51.8 & 469 & 48.7 & $1.00(0.96-1.03)$ & 0.937 \\
\hline \multicolumn{13}{|l|}{ Maternal age $(N=5268)$} \\
\hline$<20$ years & 381 & 21.3 & 236 & 26.0 & 93 & 19.7 & 274 & 24.1 & 239 & 24.8 & $1.03(0.99-1.07)$ & 0.157 \\
\hline 20-35 years & 1191 & 66.6 & 561 & 61.9 & 327 & 69.5 & 745 & 65.5 & 626 & 64.9 & & Ref. \\
\hline$>35$ years & 216 & 12.1 & 110 & 12.1 & 52 & 11.0 & 118 & 10.4 & 99 & 10.3 & $0.96(0.90-1.01)$ & 0.125 \\
\hline \multicolumn{13}{|l|}{ Skin color $(N=5267)$} \\
\hline White & 1080 & 60.4 & 575 & 63.4 & 286 & 60.7 & 690 & 60.7 & 593 & 61.5 & & Ref. \\
\hline Non-white & 707 & 39.6 & 332 & 36.6 & 186 & 39.4 & 447 & 39.3 & 371 & 38.5 & $1.00(0.96-1.03)$ & 0.888 \\
\hline \multicolumn{13}{|l|}{ SES status $(N=2709)$} \\
\hline Low & 144 & 16.0 & 92 & 19.0 & 45 & 18.0 & 135 & 23.7 & 128 & 24.6 & $1.08(1.00-1.16)$ & 0.045 \\
\hline Lower-middle & 225 & 25.1 & 126 & 26.0 & 66 & 27.9 & 150 & 26.4 & 156 & 30.0 & & Ref. \\
\hline Middle & 126 & 14.0 & 84 & 17.3 & 40 & 16.9 & 91 & 16.0 & 79 & 15.2 & $0.98(0.91-1.06)$ & 0.605 \\
\hline Upper-middle & 213 & 23.7 & 105 & 21.7 & 48 & 20.3 & 79 & 15.2 & 104 & 20.0 & $0.91(0.85-0.98)$ & 0.013 \\
\hline High & 190 & 21.2 & 78 & 16.1 & 38 & 16.0 & 104 & 20.0 & 53 & 10.2 & $0.83(0.80-0.89)$ & $<0.001$ \\
\hline \multicolumn{13}{|l|}{ Education $(N=3256)$} \\
\hline Incomplete primary & 154 & 13.2 & 90 & 16.2 & 44 & 15.8 & 101 & 14.9 & 109 & 18.9 & $1.07(1.01-1.14)$ & 0.026 \\
\hline Complete secondary & 934 & 80.0 & 439 & 79.1 & 216 & 77.7 & 551 & 81.0 & 452 & 78.5 & & Ref. \\
\hline Tertiary & 79 & 6.8 & 26 & 4.7 & 18 & 6.5 & 28 & 4.1 & 15 & 2.6 & $0.83(0.13-0.19)$ & $<0.001$ \\
\hline \multicolumn{13}{|l|}{ Diabetes $(N=3246)$} \\
\hline Yes & 36 & 3.1 & 16 & 2.9 & 6 & 2.2 & 17 & 2.5 & 16 & 2.8 & $0.95(0.83-1.09)$ & 0.500 \\
\hline \multicolumn{13}{|l|}{ Hypertension $(N=3249)$} \\
\hline Yes & 130 & 11.2 & 40 & 7.2 & 21 & 7.6 & 65 & 9.6 & 51 & 8.9 & $0.95(0.88-1.03)$ & 0.189 \\
\hline \multicolumn{13}{|c|}{ Smoke in pregnancy $(N=3240)$} \\
\hline Yes & 161 & 14.0 & 86 & 15.2 & 37 & 13.3 & 90 & 13.22 & 83 & 14.4 & $0.99(0.93-1.06)$ & 0.802 \\
\hline \multicolumn{13}{|c|}{ Drink in pregnancy $(N=3245)$} \\
\hline Yes & 161 & 13.9 & 75 & 13.5 & 40 & 14.4 & 79 & 11.6 & 66 & 11.4 & $0.94(0.88-1.01)$ & 0.079 \\
\hline \multicolumn{13}{|l|}{ Depression $(N=3251)$} \\
\hline Yes & 34 & 2.9 & 13 & 2.3 & 3 & 1.1 & 23 & 3.4 & 9 & 1.6 & $0.93(0.81-1.07)$ & 0.329 \\
\hline \multicolumn{13}{|l|}{ Physical violence $(N=3236)$} \\
\hline Yes & 27 & 2.3 & 14 & 2.5 & 4 & 1.5 & 6 & 0.9 & 7 & 1.2 & $0.79(0.66-0.95)$ & 0.013 \\
\hline
\end{tabular}

Quintiles categorized violent crimes within a 1-km from participants' home address; OR: odds ratio; 95\% Cl: 95\% confidence interval; SGA: small for gestational age; PT preterm; LBW: low birth weight; SES: socioeconomic status. * For the variables: Maternal age, SES status and Education, the values represent relative risk-ratios (RRR) 

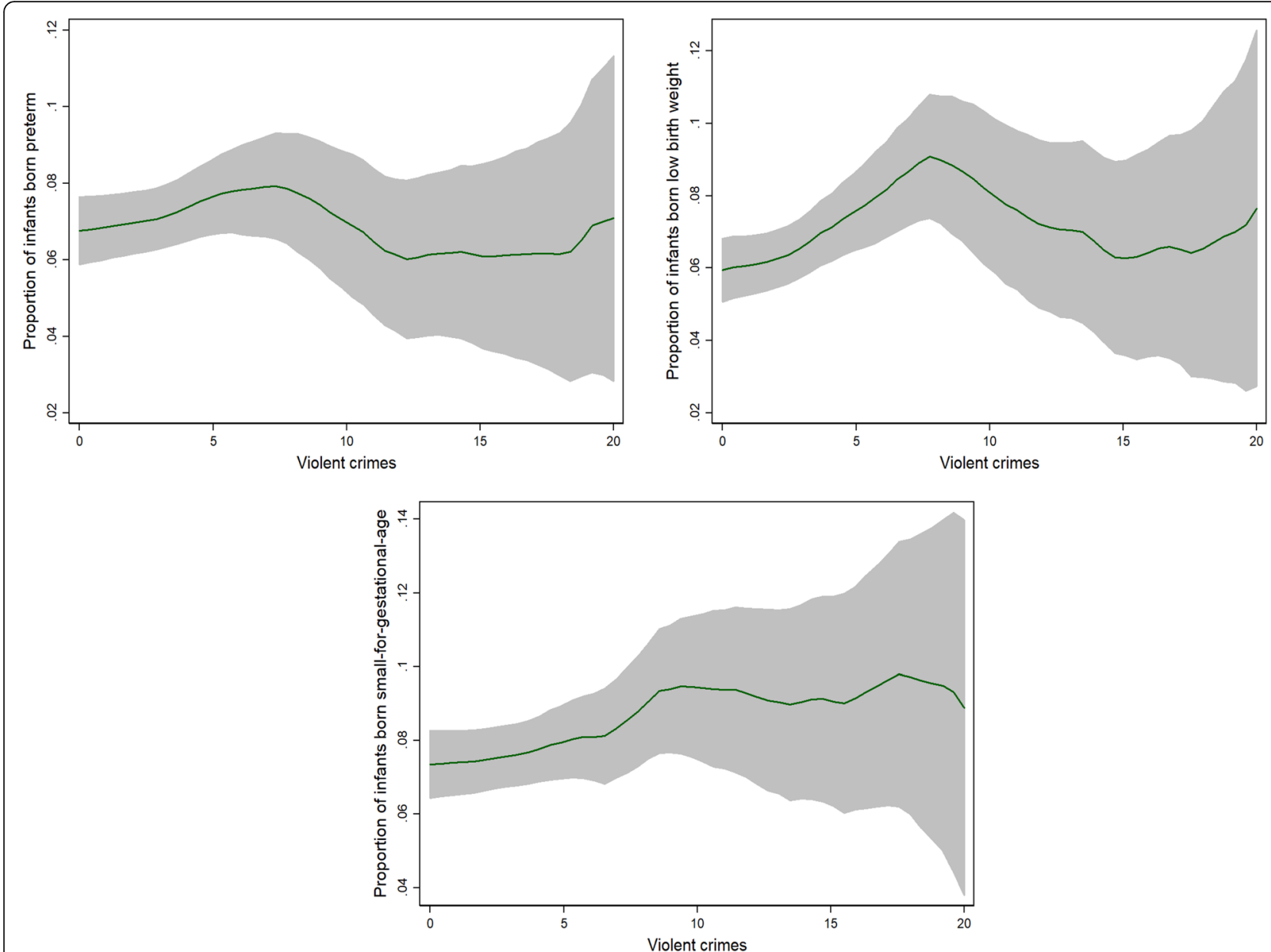

Fig. 2 Exposure to violent crime and average birth outcomes. The figure shows log polynomial smoothed relationship between violent crime exposure and preterm birth (a), low birth weight (b), and small-for-gestational-age (c)

95\%CI: 1.06-1.89). In the adjusted model, PT birth odds increased nonlinearly (Fig. 2) with violence exposure, varying the estimated ORs from 1.16 (95\%CI: 0.84-1.59) on quintile 2, 1.35 (95\%CI: $1.01-1.80)$ on quintile 4, and 1.01 (95\%CI: $0.72-$ 1.40) on quintile 5. The estimated risk of LBW increased almost linearly with exposure quintiles, with an estimated OR of 1.43 (95\%CI: 1.03-1.98) for the top quintile. In terms of the included covariates, smoking during pregnancy was the most consistent risk factor for all birth outcomes analyzed in this study, with estimated ORs of 1.83 for SGA (95\%CI: 1.322.55), 2.04 for PT birth (95\%CI: 1.47-2.82), and 2.89 for LBW (95\%CI: 2.07-4.03). Physical violence reported by the mother during pregnancy (in the post-partum interview) was associated with more than twice the odds of LBW $(2.12$; $95 \% \mathrm{CI}$ : 1.03-4.36). SES and maternal education were not associated with the outcomes in our analysis.

\section{Discussion}

This study uses a novel data set from Brazil to explore the empirical associations between neighborhood-level exposure to violent crime and birth outcomes. Our study yields three main findings: first, exposure to violent crimes is very high among pregnant women in the urban areas studied. Based on the São Paulo estimated population by the Brazilian Institute of Geography and Statistics and violent crimes reports extracted by us from the Secretariat of Public Safety of the State of São Paulo, from 2011 to 2014, there were on average 2.87 violent crimes per 10,000 inhabitants in the city of São Paulo and an average of 3.62 violent crimes per 10,000 inhabitants in the study area. While these numbers may be somewhat abstract, they imply that each person living in a densely populated area like the one studied - with an estimated density of 7770 inhabitants per $\mathrm{km}^{2}$ - experiences, on average, 0.94 violent crimes per month within 1-km walking distance from home. This implies 5.6 crimes in close vicinity within the first six months of pregnancy for the average pregnant mother. Even mothers will, with all likelihood, personally witness only a small fraction of these events, the threat of external 
Table 3 Unadjusted and adjusted analyses between violent crimes exposure during pregnancy by quintiles, and birth outcomes.

\begin{tabular}{|c|c|c|c|c|c|c|}
\hline & \multicolumn{2}{|c|}{ Unadjusted } & \multirow[b]{2}{*}{$p$} & \multicolumn{2}{|c|}{ Adjusted $^{*}$} & \multirow[b]{2}{*}{$\mathrm{p}$} \\
\hline & OR & $95 \%$ IC & & OR & $95 \% \mathrm{IC}$ & \\
\hline \multicolumn{7}{|c|}{ Small-for-gestational-age } \\
\hline \multicolumn{7}{|l|}{ Violent crimes } \\
\hline 1st quintile & Ref. & & & & & \\
\hline 2nd quintile & 1.36 & $1.02-1.83$ & 0.039 & 1.34 & $1.00-1.80$ & 0.054 \\
\hline 3rd quintile & 1.20 & $0.82-1.75$ & 0.349 & 1.19 & $0.81-1.75$ & 0.373 \\
\hline 4th quintile & 1.12 & $0.84-1.50$ & 0.418 & 1.11 & $0.84-1.50$ & 0.449 \\
\hline 5th quintile & 1.46 & $1.10-1.93$ & 0.009 & 1.41 & $1.06-1.89$ & 0.019 \\
\hline Physical violence & & & & 1.07 & $0.43-2.65$ & 0.896 \\
\hline Depression & & & & 0.42 & $0.13-1.36$ & 0.147 \\
\hline Diabetes & & & & 0.70 & $0.27-1.82$ & 0.468 \\
\hline Hypertension & & & & 1.27 & $0.82-1.95$ & 0.286 \\
\hline Smoke & & & & 1.83 & $1.32-2.55$ & $<0.001$ \\
\hline Drink & & & & 1.43 & $0.99-2.05$ & 0.055 \\
\hline
\end{tabular}

\section{Preterm birth}

$\begin{array}{lllllll}\begin{array}{c}\text { Violent crimes } \\ \text { 1st quintile }\end{array} & \text { Ref. } & & & & & \\ \text { 2nd quintile } & 1.17 & 0.86-1.59 & 0.327 & 1.16 & 0.84-1.59 & 0.367 \\ \text { 3rd quintile } & 0.98 & 0.65-1.48 & 0.918 & 1.01 & 0.66-1.54 & 0.958 \\ \text { 4th quintile } & 1.29 & 0.98-1.72 & 0.070 & 1.35 & 1.01-1.80 & 0.040 \\ \quad \text { 5th quintile } & 0.97 & 0.71-1.34 & 0.870 & 1.01 & 0.72-1.40 & 0.969 \\ \text { Physical violence } & & & & 1.62 & 0.77-3.44 & 0.206 \\ \text { Depression } & & & & 0.81 & 0.32-2.08 & 0.662 \\ \text { Diabetes } & & & & 0.94 & 0.39-2.23 & 0.884 \\ \text { Hypertension } & & & & 1.21 & 0.76-1.91 & 0.425 \\ \text { Smoke } & & & & 2.04 & 1.47-2.82 & <0.001 \\ \text { Drink } & & & & 1.18 & 0.79-1.76 & 0.420\end{array}$

Low birth weight

\begin{tabular}{ccccccc}
$\begin{array}{c}\text { Violent crimes } \\
\text { 1st quintile }\end{array}$ & Ref. & & & & & \\
2nd quintile & 1.38 & $1.00-1.91$ & 0.050 & 1.37 & $0.98-1.91$ & 0.063 \\
3rd quintile & 1.32 & $0.88-1.99$ & 0.178 & 1.36 & $0.89-2.07$ & 0.153 \\
4th quintile & 1.48 & $1.10-1.99$ & 0.010 & 1.50 & $1.11-2.05$ & 0.009 \\
5th quintile & 1.42 & $1.04-1.95$ & 0.029 & 1.42 & $1.03-1.98$ & 0.034 \\
Physical violence & & & & 2.12 & $1.03-4.36$ & 0.042 \\
Depression & & & & 0.71 & $0.22-2.25$ & 0.557 \\
Diabetes & & & & 0.30 & $0.07-1.30$ & 0.107 \\
Hypertension & & & & 1.73 & $1.10-2.71$ & 0.017 \\
Smoke & & & & 2.89 & $2.07-4.03$ & $<0.001$ \\
Drink & & & & 1.14 & $0.77-1.69$ & 0.522 \\
\hline OR:
\end{tabular}

OR: odds ratio; $95 \% \mathrm{Cl}$ : 95\% confidence interval; All analyses used multiple imputations. Imputed data were averaged across the 50 imputed data sets using Rubin's rule [41]. *Adjusted for maternal age, child sex (female), education, and socioeconomic status violence is, without any doubt, real and constantly present.

Second, our results suggest that external violence should not be interpreted as homogeneous characteristics of entire cities or larger census tracts, but something highly heterogeneous within relatively small spatial areas. As shown in Fig. 1, the distance between some of the safest and some of the most violent exposed neighborhoods is less than $2 \mathrm{~km}$, highlighting the remarkable small scale at which urban disparities can be detected.

Third, and maybe most importantly, we found that exposure to crime is associated with substantial SGA, PT, and LBW increases even after controlling for SES status and maternal education, and other risk factors. Our findings that violence increases adverse birth outcomes are consistent with a previous municipality-level comparison from Brazil [27] and highlight the critical long-term consequences of violence beyond the immediate impact on the directly affected population. However, in their study, the authors found a pronounced difference among children of poorly educated mothers, suggesting that violence is only a component of the disadvantages that these children are exposed to due to low SES [27]. Similarly, another study found that neighborhood-level socio-economic-related risks directly affect LBW and PT, and these effects are mediated by personal-level risks such as SES status [17]. Despite the evidence, the pathways connecting neighborhood-level social and environmental conditions to individual-level adverse birth outcomes remain poorly understood. Differences in birth outcomes across different socioeconomic levels could be due to psychosocial stressors [17, 54], which could trigger adverse birth outcomes through a series of behavioral and neuroendocrinal interactions affecting the intrauterine environment $[7,15-19,21-23,55]$.

The general literature on violence exposure and birth outcomes has been more mixed with some studies such as Messer et al. [26], finding no associations with adverse birth outcomes and others such as Goin et al. [29], finding only an association between first-trimester exposure and SGA. While several theoretical mechanisms highlighted in the literature and introduction of this paper seem consistent with the results presented here, we do not have data to directly investigate mechanisms such as blood pressure increases [56] and anxiety [57] highlighted in the literature. HPA axis activation would be consistent with the PT delivery increase documented in several epidemiological studies [20-22, 58, 59]. It is also possible that heightened maternal cortisol levels may lead to increased placental corticotrophin and prostanoid release. This can stimulate uterine contractions, induce preterm delivery [17, 20-23], and cause intrauterine growth restriction [7]. Although placental enzymes protect the fetus from increased maternal cortisol 
levels in principle, animal studies suggest that prenatal stress can affect the placental activity and in utero enzyme expression $[60,61]$.

Our results corroborate the previous literature and add to the understanding of violence and its influence on health in a densely populated and heterogenous setting in an LMIC. Although our study did not explore the direct violence against pregnant women, previous findings suggest that domestic violence against pregnant women and mental disorders during pregnancy can have detrimental effects on birth outcomes in the Western Region of São Paulo [62]. The pathways between psychosocial stressors, like indirect and direct violence during pregnancy, and adverse birth outcomes, are poorly understood. Still, both negatively affect maternal and child health, possibly, by a common pathway.

Rapid rates of urbanization combined with increasing economic and gender inequalities are likely to trigger increased rates of violent crime and lead to a higher prevalence of risk factors in many settings, especially in areas where access to basic education and health care services remains limited $[63,64]$. High violence rates may also endorse and strengthen social and cultural norms around masculinity and gendered power relationships [65]. Intersectoral strategies to decrease violence are urgently needed, and health programs must be improved to support victims of all kinds of violence.

\section{Limitations}

The analysis presented in this paper has some limitations. The ROC-cohort enrolled mother-child dyads at the delivery, and important risk factors such as diabetes, hypertension, and physical violence were assessed only through the postpartum questionnaire. Those variables were in the analysis as "yes/no" did not assess the extent or in which period of the pregnancy it occurred. Moreover, smoking and drinking were assessed in five categories ranging from "never" to "every day", and in both variables, almost $90 \%$ fell in the first category (never). Therefore, we decided to recode to "yes/no", since we also could not know which period of the pregnancy occurred. Another limitation is that in our post-partum questionnaire we did not collect information related to intimate partner abuse (physical, emotional, financial), rape, and child sexual assault which could influence women's sense of safety that could impact pregnancy outcomes.

Although violence exposure during the third trimester of pregnancy is likely to trigger adverse birth outcomes, our study only considered violence exposure during the first two trimesters of pregnancy. The primary reason for this was the presence of early preterm children (2428 gestational weeks) in our sample, which did not allow us to compute third-trimester exposure variables.
Excluding these cases or computing only partial exposures would likely have resulted in substantial estimation bias. It is also not clear how complete the violence data is. The National System of Statistics on Public Security and Criminal Justice [66] classifies each State as having low, medium, or high-quality data, according to the extent of its data coverage and the proportion of deaths with undetermined causes, and São Paulo is in the highquality group data. It is possible that our data still underestimates the number of crimes in the area because of non-reported or non-registered crimes because, in disadvantaged areas, the residents tend to report only the most salient crimes. However, we believe that this type of measurement error should be small in the studied setting due to the extensive policing and the relatively high economic development levels.

\section{Conclusions}

The results presented in this paper suggest that living in a neighborhood with high rates of violent crime is associated with substantial increases in small-for-gestationalage, preterm and low birth weight births. Actions to improve neighborhood safety and to prevent violence could reduce inequalities among disadvantaged populations with likely substantial long-term benefits on population health and wellbeing.

\section{Abbreviations}

HIC: High-income countries; LMICs: Low-middle-income countries; ROCCohort: Western Region Birth Cohort (Região Oeste Coorte); LBW: Low birth weight; PT: Preterm delivery; SGA: Small-for-gestational-age;

SES: Socioeconomic status; PCA: Principal component analysis; MICE: Multiple imputations by chained eqs.; 95\%Cl: 95\% confidence interval; RRR: Relative Risk-Ratio; SD: Standard deviation; OR: Odds ratio

\section{Supplementary Information}

The online version contains supplementary material available at https://doi. org/10.1186/s12889-021-10900-y.

Additional file 1 Supplementary file 1: Postpartum questionnaire. Additional file 2 Supplementary file 2: Multiple imputations. Table S1. Missingness among variables used in the multiple imputation models.

\section{Acknowledgments}

Not applicable.

\section{Authors' contributions}

$A C S, A B$, and GF contributed to the conception and design of the study. ACS coded the exposure data collection and geocoding, designed the maps, tables and figures, performed the statistical analysis and drafted the manuscript. $A B$, as the principal investigator of the ROC-Cohort, coordinated and supervised data collection, contributed to the analysis and interpretation of the results, and critically reviewed the manuscript. GF supervised data collection, cleaned the data, provided the analysis plan, contributed to the analysis and interpretation of the results, and critically reviewed the manuscript. All authors read and approved the final version of the manuscript.

\section{Funding}

This study was financed in part by the Coordenação de Aperfeiçoamento de Pessoal de Nível Superior - Brasil (CAPES) - Finance Code 001. The funding 
agency had no role in the analysis, collection, and interpretation of data, nor did it in the writing process.

\section{Availability of data and materials}

The violence information used in this study is publicly available at the Secretariat of Public Safety of the State of São Paulo webpage: www.ssp.sp. gov.br. The individual data that support the findings of this study include personal information such as residential address and health-related data. Therefore, the data are not publicly available. The data can be made available upon reasonable request to the corresponding author after obtaining permission from the University Hospital of the School of Medicine of the University of São Paulo's Ethics board in accordance with the ethics policy statements related to the study protocol.

\section{Declarations}

\section{Ethics approval and consent to participate}

The Ethics Committee for the Analysis of Research Projects (Comissão de Ética para Análise de Projetos de Pesquisa, CAPPesq) of the University Hospital of the School of Medicine of the University of São Paulo (HCFMUSP) approved this study under protocol number: 01604312.1.0000.0065. All mothers who agreed to participate in the ROC-Cohort signed the consent form after being informed about the study and after all questions were answered by trained interviewers.

\section{Consent for publication}

Not applicable.

\section{Competing interests}

The authors declare that they have no competing interests.

\section{Author details}

${ }^{1}$ Department of Pediatrics, University of São Paulo Medical School, Av. Dr. Enéas Carvalho de Aguiar, 647, São Paulo CEP-01246-904, Brazil. ²Department of Epidemiology and Public Health University of Basel, Swiss Tropical and Public Health Institute, Basel, Switzerland.

Received: 7 July 2020 Accepted: 23 April 2021

Published online: 05 May 2021

\section{References}

1. Blencowe $H$, Krasevec J, de Onis M, Black RE, An X, Stevens GA, et al. National, regional, and worldwide estimates of low birthweight in 2015, with trends from 2000: a systematic analysis. Lancet Glob Heal. 2019;7(7): e849-60. https://doi.org/10.1016/S2214-109X(18)30565-5.

2. Chawanpaiboon S, Vogel JP, Moller A-B, Lumbiganon P, Petzold M, Hogan D, et al. Global, regional, and national estimates of levels of preterm birth in 2014: a systematic review and modelling analysis. Lancet Glob Heal. 2019; 7(1):e37-46. https://doi.org/10.1016/S2214-109X(18)30451-0.

3. Barker DJ, Osmond C. Infant mortality, childhood nutrition, and ischaemic heart disease in England and Wales. Lancet (London, England). 1986;1:107781 http://www.ncbi.nlm.nih.gov/pubmed/2871345.

4. Kramer MS. Determinants of low birth weight : methodological assessment and meta-analysis / M. S. Kramer. Bull World Heal Organ. 1987;65(5):663737.

5. Seckl JR, Holmes MC. Mechanisms of disease: glucocorticoids, their placental metabolism and fetal "programming" of adult pathophysiology. Nat Clin Pract Endocrinol Metab. 2007;3(6):479-88. https://doi.org/10.1038/ ncpendmet0515.

6. O'Donnell K, O'Connor TG, Glover V. Prenatal stress and neurodevelopment of the child: focus on the HPA Axis and role of the placenta. Dev Neurosci. 2009;31(4):285-92. https://doi.org/10.1159/000216539.

7. Lewis AJ, Austin E, Galbally M. Prenatal maternal mental health and fetal growth restriction: a systematic review. J Dev Orig Health Dis. 2016;7(4):41628. https://doi.org/10.1017/S2040174416000076.

8. World Health Assembly 49. Prevention of violence: public health priority. Geneva: WHO: World Health Organization; 1996. https://apps.who.int/iris/ha ndle/10665/179463.

9. Krug EG, et al. World report on violence and health. Geneva: World Health Organization; 2002.
10. World Health Organization. Global status report on violence prevention 2014. Geneva: World Health Organization; 2014. https://apps.who.int/iris/ha ndle/10665/145086.

11. World Health Organization. Health in 2015: from MDGs, millennium development goals to SDGs, sustainable development goals. Geneva: World Health Organization; 2015. https://www.who.int/violence_injury_prevention/ violence/status_report/2014/en/.

12. García-Moreno C, Pallitto C, Devries K, Stöckl H, Watts C, Abrahams N, et al. Global and regional estimates of violence against women: prevalence and health effects of intimate partner violence and non-partner sexual violence. Geneva: World Health Organization; 2013. https://apps.who.int/iris/bitstrea m/handle/10665/85239/9789241564625_eng.pdf?sequence=1.

13. Ross CE, Mirowsky J. Neighborhood disadvantage, disorder, and health. J Health Soc Behav. 2001;42(3):258-76. http://www.ncbi.nlm.nih.gov/ pubmed/11668773. https://doi.org/10.2307/3090214.

14. Lorenc T, Petticrew M, Whitehead M, Neary D, Clayton S, Wright K, et al. Fear of crime and the environment: systematic review of UK qualitative evidence. BMC Public Health. 2013;13(1):496. https://doi.org/10.1186/1471-24 58-13-496.

15. Séguin L, Potvin L, St. Denis M, Loiselle J. Chronic stressors, social support, and depression during pregnancy. Obstet Gynecol 1995;85:583-589. doi: https://doi.org/https://doi.org/10.1016/0029-7844(94)00449-N, 4.

16. Lydon J, Dunkel-Schetter C, Cohan CL, Pierce T. Pregnancy decision making as a significant life event: a commitment approach. J Pers Soc Psychol. 1996;71(1):141-51. https://doi.org/10.1037/0022-3514.71.1.141.

17. Meng G, Thompson ME, Hall G. Pathways of neighbourhood-level socioeconomic determinants of adverse birth outcomes. Int J Health Geogr. 2013;12(1):32. https://doi.org/10.1186/1476-072X-12-32.

18. Perloff JD, Jaffee KD. Late entry into prenatal care: the neighborhood context. Soc Work. 1999;44(2):116-28. https://doi.org/10.1093/sw/44.2.116.

19. Diez Roux AV. Residential environments and cardiovascular risk. J Urban Health. 2003;80(4):569-89. https://doi.org/10.1093/jurban/jtg065.

20. McEwen BS. Physiology and neurobiology of stress and adaptation: central role of the brain. Physiol Rev. 2007;87(3):873-904. https://doi.org/10.1152/ physrev.00041.2006.

21. Wadhwa PD, Garite TJ, Porto M, Glynn L, Chicz-DeMet A, Dunkel-Schetter C, et al. Placental corticotropin-releasing hormone $(\mathrm{CRH})$, spontaneous preterm birth, and fetal growth restriction: A prospective investigation. Am J Obstet Gynecol. 2004;191(4):1063-9. https://doi.org/10.1016/j.ajog.2004.06.070.

22. Beijers $\mathrm{R}$, Buitelaar JK, de Weerth C. Mechanisms underlying the effects of prenatal psychosocial stress on child outcomes: beyond the HPA axis. Eur Child Adolesc Psychiatry. 2014;23(10):943-56. https://doi.org/10.1007/ s00787-014-0566-3.

23. Majzoub JA, Karalis KP. Placental corticotropin-releasing hormone: function and regulation. Am J Obstet Gynecol. 1999;180(1):S242-6. https://doi.org/1 0.1016/S0002-9378(99)70708-8

24. Zapata BC, Rebolledo A, Atalah E, Newman B, King MC. The influence of social and political violence on the risk of pregnancy complications. Am J Public Health. 1992;82(5):685-90. https://doi.org/10.2105/AJPH.82.5.685.

25. Morenoff JD. Neighborhood mechanisms and the spatial dynamics of birth weight. Am J Sociol. 2003;108(5):976-1017. https://doi.org/10.1086/374405.

26. Messer LC, Kaufman JS, Dole N, Herring A, Laraia BA. Violent crime exposure classification and adverse birth outcomes: a geographically-defined cohort study. Int J Health Geogr. 2006;5(1):22. https://doi.org/10.1186/1476-072X-5-22.

27. Foureaux Koppensteiner M, Manacorda M. Violence and birth outcomes: evidence from homicides in Brazil. J Dev Econ. 2016;119:16-33. https://doi. org/10.1016/j.jdeveco.2015.11.003.

28. Matoba N, Reina M, Prachand N, Davis MM, Collins JW. Neighborhood gun violence and birth outcomes in Chicago. Matern Child Health J. 2019;23(9): 1251-9. https://doi.org/10.1007/s10995-019-02765-w.

29. Goin DE, Gomez AM, Farkas K, Zimmerman SC, Matthay EC, Ahern J. Exposure to community homicide during pregnancy and adverse birth outcomes. Epidemiology. 2019;30(5):713-22. https://doi.org/10.1097/EDE. 0000000000001044.

30. Mayne SL, Pool LR, Grobman WA, Kershaw KN. Associations of neighbourhood crime with adverse pregnancy outcomes among women in Chicago: analysis of electronic health records from 2009 to 2013. J Epidemiol Community Health. 2018;72(3):230-6. https://doi.org/10.1136/jech-2017-209801.

31. Felker-Kantor $E$, Wallace $M$, Theall K. Living in violence: neighborhood domestic violence and small for gestational age births. Health Place. 2017; 46:130-6. https://doi.org/10.1016/j.healthplace.2017.05.011. 
32. Messer LC, Kaufman JS, Dole N, Savitz DA, Laraia BA. Neighborhood crime, deprivation, and preterm birth. Ann Epidemiol. 2006;16(6):455-62. https:// doi.org/10.1016/j.annepidem.2005.08.006.

33. Clemens T, Dibben C. Living in stressful neighbourhoods during pregnancy: an observational study of crime rates and birth outcomes. Eur J Public Health. 2016;27(2):197-202. https://doi.org/10.1093/eurpub/ckw131.

34. Brown R. The Mexican drug war and early-life health: the impact of violent crime on birth outcomes. Demography. 2018;55(1):319-40. https://doi.org/1 0.1007/s13524-017-0639-2.

35. Urdinola-Contreras BP. War is not healthy. Political violence and infant health outcomes in Colombia. Rev Salud Pública. 2018;20:326-s. https://doi. org/10.15446/rsap.v20n3.55430

36. Comacho A. Stress and birth weight: evidence from terrorist attacks. Am Econ Rev. 2008;98(2):511-5. http://www.ncbi.nlm.nih.gov/pubmed/2913 5213. https://doi.org/10.1257/aer.98.2.511.

37. Geronimus AT. The weathering hypothesis and the health of AfricanAmerican women and infants: evidence and speculations. Ethn Dis. 1992;2: 207-21 http://europepmc.org/abstract/MED/1467758.

38. United Nations, Department of Economic and Social Affairs, Population Division. World urbanization prospects: the 2018 revision (ST/ESA/SER.A/ 420). New York: United Nations; 2019.

39. Fundação Seade. Proporção de Nascidos Vivos com menos de 37 semanas de gestação em relação ao total de Nascidos Vivos. 2021. https://perfil.sea de.gov.br. Accessed 21 Feb 2021.

40. Fundação Seade. Proporção de Nascidos Vivos com peso inferior a 2,5 kg em relação ao total de Nascidos Vivos. 2021. https://perfil.seade.gov.br Accessed 21 Feb 2021

41. Cardia N. Urban Violence in São Paulo. Washington: Woodrow Wilson International Center for Scholars (Comparative Urban Studies Occasional Papers Series, 33); 2000.

42. World Bank. GINI index. 2020. https://data.worldbank.org/indicator/SI.POV. GINI. Accessed 24 May 2020

43. Cerqueira D, Bueno S, Lima RS de, Cristina N, Helder F, Paloma Palmieri A, et al. Atlas da violência 2019. São Paulo: Instituto de Pesquisa Econômica Aplicada (Ipea); 2019.

44. Rodrigues A, Hernandes R, Mariani D, Bergamo M. Mapa da morte em SP. 2017. http://temas.folha.uol.com.br/mapa-da-morte/introducao/mapa-damorte-em-sp-vai-da-suecia-ate-o-mexico-locais-dos-crimes-se-repetem.shtml. Accessed 15 February 2020

45. Brentani A, Scoleze Ferrer AP, Brentani H, Liu CH, Grisi SJFE, Valente MH, et al. Cohort profile: São Paulo Western region birth cohort (ROC). Int J Epidemiol. 2020;49(5):1438-1438g. https://doi.org/10.1093/ije/dyaa129.

46. Ballard JL, Khoury JC, Wedig K, Wang L, Eilers-Walsman BL, Lipp R. New Ballard score, expanded to include extremely premature infants. J Pediatr. 1991;119(3):417-23. https://doi.org/10.1016/S0022-3476(05)82056-6.

47. Villar J, Ismail LC, Victora CG, Ohuma EO, Bertino E, Altman DG, et al. International standards for newborn weight, length, and head circumference by gestational age and sex: the newborn cross-sectional study of the INTERGROWTH-21st project. Lancet. 2014;384(9946):857-68. https://doi.org/10.1016/S0140-6736(14)60932-6.

48. Kahle D, Wickham H. Ggmap spatial visualization with ggplot2. R J. 2013; 5(1):144-61. httpsjournal.r-project.orgarchive2013-1 kahle-wickham.pdf. https://doi.org/10.32614/RJ-2013-014.

49. R Core Team. R: A Language and Environment for Statistical Computing. 2019. http://www.r-project.org/.

50. Vyas S, Kumaranayake L. Constructing socio-economic status indices: how to use principal components analysis. Health Policy Plan. 2006;21(6):459-68. https://doi.org/10.1093/heapol/czl029.

51. StataCorp. Stata 14 base reference manual. College Station: Stata Press; 2015.

52. Rubin DB. Multiple imputation for nonresponse in surveys. Hoboken: Wiley; 2004.

53. StataCorp. Stata statistical software: release 14. College Station: StataCorp LP; 2015.

54. Elstad Jl. The psycho-social perspective on social inequalities in health. Soc Heal IIIn. 1998;20(5):598-618. https://doi.org/10.1111/1467-9566.00121.

55. McEwen BS. Protective and damaging effects of stress mediators. N Engl J Med. 1998;338(3):171-9. https://doi.org/10.1056/NEJM199801153380307.

56. Wilson DK, Kliewer W, Sica DA. The relationship between exposure to violence and blood pressure mechanisms. Curr Hypertens Rep. 2004;6(4): 321-6. https://doi.org/10.1007/s11906-004-0028-2.
57. Pynoos RS. Traumatic stress and developmental psychopathology in children and adolescents. In: Oldham JM, Riba MB and Tasman A, editor. American Psychiatric Press Review of Psychiatry. Vol. 12. Washington: American Psychiatric Association; 1993.

58. Giurgescu C. Are maternal cortisol levels related to preterm birth? J Obstet Gynecol Neonatal Nurs. 2009;38(4):377-90. https://doi.org/10.1111/j.15526909.2009.01034.x

59. Compas BE. Psychobiological processes of stress and coping: implications for resilience in children and adolescents--comments on the papers of Romeo \& McEwen and fisher et al. Ann N Y Acad Sci. 2006;1094(1):226-34. https://doi.org/10.1196/annals.1376.024.

60. Mairesse J, Lesage J, Breton C, Bréant B, Hahn T, Darnaudéry M, et al. Maternal stress alters endocrine function of the feto-placental unit in rats. Am J Physiol Metab. 2007;292(6):E1526-33. https://doi.org/10.1152/ajpendo. 00574.2006.

61. Jensen Peña C, Monk C, Champagne FA. Epigenetic effects of prenatal stress on 11ß-hydroxysteroid dehydrogenase-2 in the placenta and fetal brain. PLoS One. 2012;7(6):e39791. https://doi.org/10.1371/journal.pone.003 9791.

62. Ferraro AA, Rohde LA, Polanczyk GV, Argeu A, Miguel EC, Grisi SJFE, et al. The specific and combined role of domestic violence and mental health disorders during pregnancy on new-born health. BMC Pregnancy Childbirth. 2017;17(1):257. https://doi.org/10.1186/s12884-017-1438-x.

63. World Health Organization. Global report on urban health: equitable healthier cities for sustainable development. Geneva: World Health Organization; 2016. https://apps.who.int/iris/handle/10665/204715.

64. Unicef. The state of the world's children 2012: children in an urban world. eSocialSciences; 2012

65. Yount KM, James-Hawkins L, Cheong YF, Naved RT. Men's perpetration of partner violence in Bangladesh: community gender norms and violence in childhood. Psychol Men Masc. 2018;19(1):117-30. https://doi.org/10.1037/ men0000069.

66. Lima RS de, Bueno S, Martins C, Marques D, Pröglhöf PN, Astolfi R, et al. $9^{\circ}$ Anuário Brasileiro de Segurança Pública. São Paulo, SP; 2015. https:/doi.org/ https://www.forumseguranca.org.br/storage/9_anuario_2015.retificado_.pdf.

\section{Publisher's Note}

Springer Nature remains neutral with regard to jurisdictional claims in published maps and institutional affiliations.
Ready to submit your research? Choose BMC and benefit from:

- fast, convenient online submission

- thorough peer review by experienced researchers in your field

- rapid publication on acceptance

- support for research data, including large and complex data types

- gold Open Access which fosters wider collaboration and increased citations

- maximum visibility for your research: over $100 \mathrm{M}$ website views per year

At $\mathrm{BMC}$, research is always in progress.

Learn more biomedcentral.com/submissions 